\title{
Application of seismic multi-attribute inversion based on wireless network sensor in Dongying delta foreset
}

\author{
YuanyuanWang ${ }^{1,2^{*}}$ and CuiWang ${ }^{1}$
}

\author{
* Correspondence: yyw@hpu.edu.cn \\ 1 Institute of Resource and \\ Environment, Henan Polytechnic \\ University, Jiaozuo 454003, China \\ ${ }^{2}$ Henan Key Laboratory of Biogenic \\ Traces \& Sedimentary Minerals of \\ Henan Province, Jiaozuo 454003, \\ China
}

\begin{abstract}
Seismic attributes, which are extracted from seismic information, are physical indexes used specifically for the measurement of geometric, dynamic, or statistical characteristics of seismic data. Current methods for seismic multiattribute inversion include linear and nonlinear methods. By adopting the wireless module of NFC24101, combined with the seismic data acquisition sensor, constitutes an intelligent network sensor, and then it sends the collected data to the topmost machine for analysis. Methods for the nonlinear inversion of seismic multi-attributes usually employ tools such as neural networks and support vector machines (SVMs) for mapping. Hence, inversion results obtained via nonlinear methods are more accurate than those obtained via linear methods. In this work, with spontaneous-potential (SP) curves as the objective of nonlinear inversion, an optimized seismic attribute combination for the inversion of SP curves was identified, and the nonlinear inversion of seismic multi-attributes was achieved via the use of a deep neural network (DNN) to obtain 3D SP data. Finally, the foresetting process of a sand body of the intermediate section in Member 3 of the Shahejie Formation in the Dongying Delta was illustrated via the horizon slice of the SP data.

Keywords: Sensor network, Seismic multi-attribute inversion, Deep neural network, Delta foreset
\end{abstract}

\section{Introduction}

Seismic attributes are closely related to reservoir parameters. However, the seismic data acquisition way is less concerned. Wireless sensor network (WSN) is a set of advanced technology in the integration of information technology, it is not only a universal computer, and also the effective extension of human senses, the data transmission and exchange as the center, as a kind of self-organized and distributed network, a large number of sensor nodes in sensor network to provide the data, even in very poor conditions, also can do real-time monitoring, cooperative awareness and information collection, and send the monitoring data. This makes wireless sensor networks widely used in many fields.

(c) The Author(s). 2020 Open Access This article is licensed under a Creative Commons Attribution 4.0 International License, which permits use, sharing, adaptation, distribution and reproduction in any medium or format, as long as you give appropriate credit to the original author(s) and the source, provide a link to the Creative Commons licence, and indicate if changes were made. The images or other third party material in this article are included in the article's Creative Commons licence, unless indicated otherwise in a credit line to the material. If material is not included in the article's Creative Commons licence and your intended use is not permitted by statutory regulation or exceeds the permitted use, you will need to obtain permission directly from the copyright holder. To view a copy of this licence, visit http://creativecommons.org/licenses/by/4.0/. 
Seismic attribute analysis involves the prediction of reservoir parameters based on seismic attributes [1-3] and has played an increasingly important role in the exploration and exploitation of oil and gas. Seismic attributes are closely related to reservoir parameters [4], but they have no direct analytic relation. The basic concept of the nonlinear inversion of seismic multi-attributes $[5,6]$ is to establish a nonlinear relation of seismic multiattributes and reservoir parameters via mathematical methods (e.g., multi-variable stepwise regression, neural networks, support vector machines (SVMs), and the co-Kriging method [7-9]) and obtain information required by reservoir prediction.

In this work, spontaneous-potential (SP) curves were employed as the objective of the nonlinear inversion of seismic multi-attributes. First, an optimized seismic attribute combination for the inversion of SP curves was identified via nonlinear regression. Then, 3D SP data was obtained by the nonlinear inversion of seismic multi-attributes based on a deep neural network (DNN). Finally, the foresetting process of a sand body of the intermediate section in Member 3 of the Shahejie Formation in the Dongying Delta was illustrated by the horizon slice of the SP data body. The practical application results indicate the good application performance and great potential of the proposed nonlinear inversion of seismic multi-attributes.

\section{Principles and methods}

\subsection{Optimization of seismic attributes}

The optimization of seismic attributes aims to retrieve the optimized attribute combination from various seismic attributes via stepwise regression methods [10]. First, the correlations between each single attribute and the conversion curve were calculated, and the attribute with the highest correlation was retained. Then, the second, third,..., $x$ th (where $x$ refers to the designated maximum attribute number) optimized attributes were retrieved from the remaining attributes according to the root mean square criterion.

\subsection{Convolution operator}

The value of the parameter to be inverted at the sampling point of the curve is dependent on both its attribute and several points above and below the corresponding seismic attribute point. Therefore, the value of the parameter to be inverted at the sampling point of the curve is correlated to points above and below the corresponding seismic attribute point to further improve the stability of the multi-attribute inversion solution. This can be achieved by the convolution operator:

$$
L=\omega_{0}+w_{1}^{m} * A_{1}+w_{2}^{m} * A_{2}+\ldots+w_{n}^{m} * A_{n},
$$

where $L$ refers to the parameter to be inverted, $\omega_{0}$ is a constant, $w_{1}^{m}, w_{2}^{m}, \cdots, w_{n}^{m}$ are convolution operators, $m$ refers to the length of the convolution operator, and $A_{1}$, $A_{2}, \cdots, A_{n}$ are $N$ attributes retrieved via the optimization of attribute combination.

Equation (1) can be simplified as:

$$
L=A w
$$

For accurate data model parameters, the convolution operator can be expressed as:

$$
w=A^{-1} L
$$

However, practical data cannot accurately fit the model due to experimental error: 


$$
L=A w+e_{i}
$$

where $e_{i}$ refers to the error.

The most effective way to obtain the unique solution of a model parameter is the minimization of the sum of square of errors:

$$
q=e^{T} e=\sum_{i=1}^{5}\left(L_{i}-\sum_{j=1}^{12} A_{i j} w_{j}\right)^{2}
$$

or

$$
q=(L-A w)^{T}(L-A w)
$$

where $q$ refers to the sum of square of errors, $T$ refers to the matrix transposition, $L_{i}$ refers to the parameter to be inverted, $A_{i j}$ refers to the seismic attribute, and $w_{j}$ refers to the convolution operator.

The derivation of Eq. (6) leads to:

$$
\frac{\partial q}{\partial w_{j}}=\frac{\partial\left[L^{T} L-L^{T} A w-w^{T} A^{T} L+w^{T} A^{T} A w\right]}{\partial w_{j}}
$$

The canonical equation is:

$$
2 A^{T} A w=2 A^{T} L
$$

The estimated least squares solution of the parameter can be obtained:

$$
\hat{w}=\left[A^{T} A\right]^{-1} A^{T} L
$$

In this way, the convolution operator is obtained.

\subsection{Deep neural network}

A DNN is essentially a modified version of conventional neural networks, and its structure is illustrated in Fig. 1. A typical DNN consists of an input layer, output layer, and several hidden layers. Each layer has several nodes that are connected by weights, and the results of

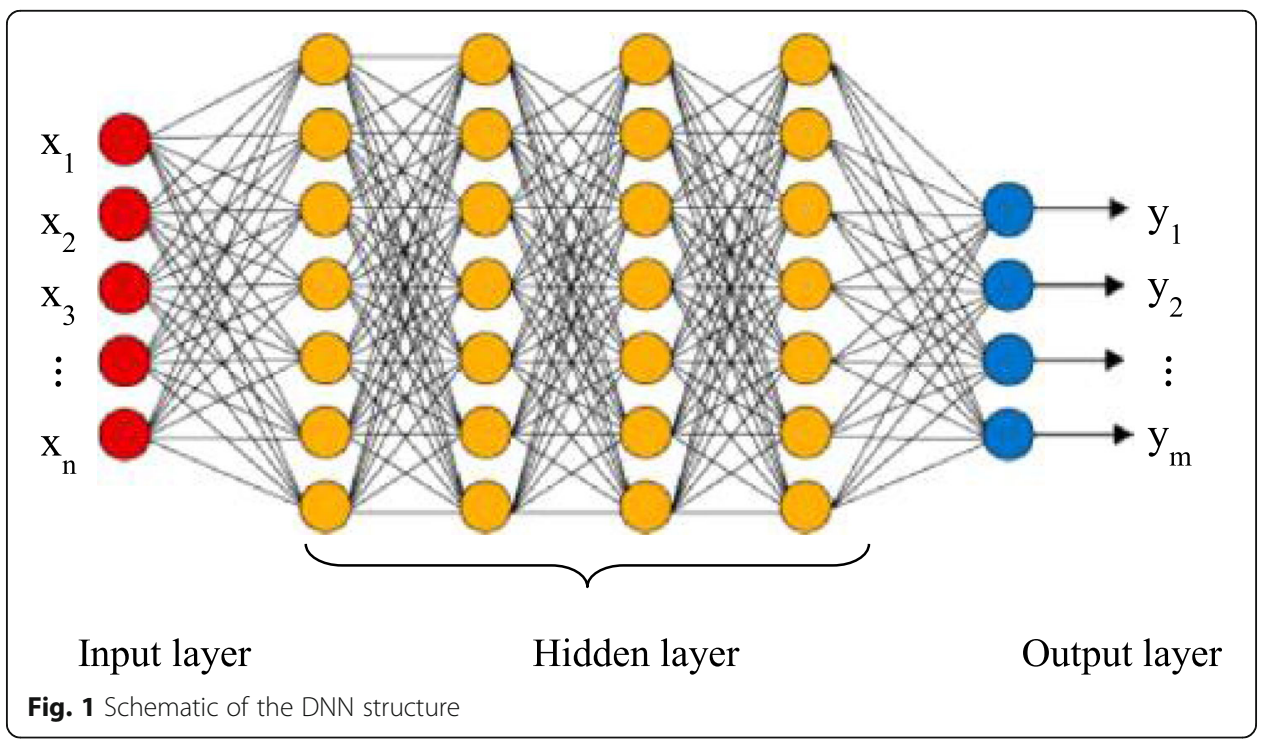


the output layer are determined by the weights $[11,12]$. In this study, a DNN consisting of one input layer, one output layer, and three hidden layers was used. Herein, a convolution operator is involved, and the seismic attribute is convoluted with the convolution operator before being used as the input of the DNN.

The optimized weights of nodes in hidden layers can be calculated via the learning process of the DNN, and network training can be realized by employing a training set as the input of the DNN. Weight determination can be regarded as a nonlinear optimization process, the objective of which is the minimization of the mean square error of the practical target log value and predicted target log value. Solutions can be obtained by methods such as back propagation [11, 12].

In summary, seismic multi-attribute inversion involves the establishment of a nonlinear relation of seismic multi-attributes and SP via mathematical methods. The SPs of strata are calculated based on the log data of known wells, and the lithology of strata can be identified by the inversion of SP parameters based on seismic data $[13,14]$.

\section{Practical applications}

Delta is a product of the combination of water basin, the river input, tides, waves, and the impact of factors such as tectonic and climate, with complex composition and sedimentary characteristics and sedimentary environment. Delta is a kind of very important sedimentary environment. Many oil fields in China, such as Daqing Oil Field, Shengli Oil Field, Changqing gas field, Xinjiang oilfield, and delta sand body, are main reservoir and are an important part in oil and gas gathering. For Member 3 of the Shahejie Formation in the Dongying Delta, the sedimentary period was the peak of fault subsidence $[15,16]$, during which large scale delta systems were developed. In previous studies [17, 18], the intermediate section in Member 3 of the Shahejie Formation in Dongying Delta was divided into nine stages (labeled as z1 through z9). However, the distribution range

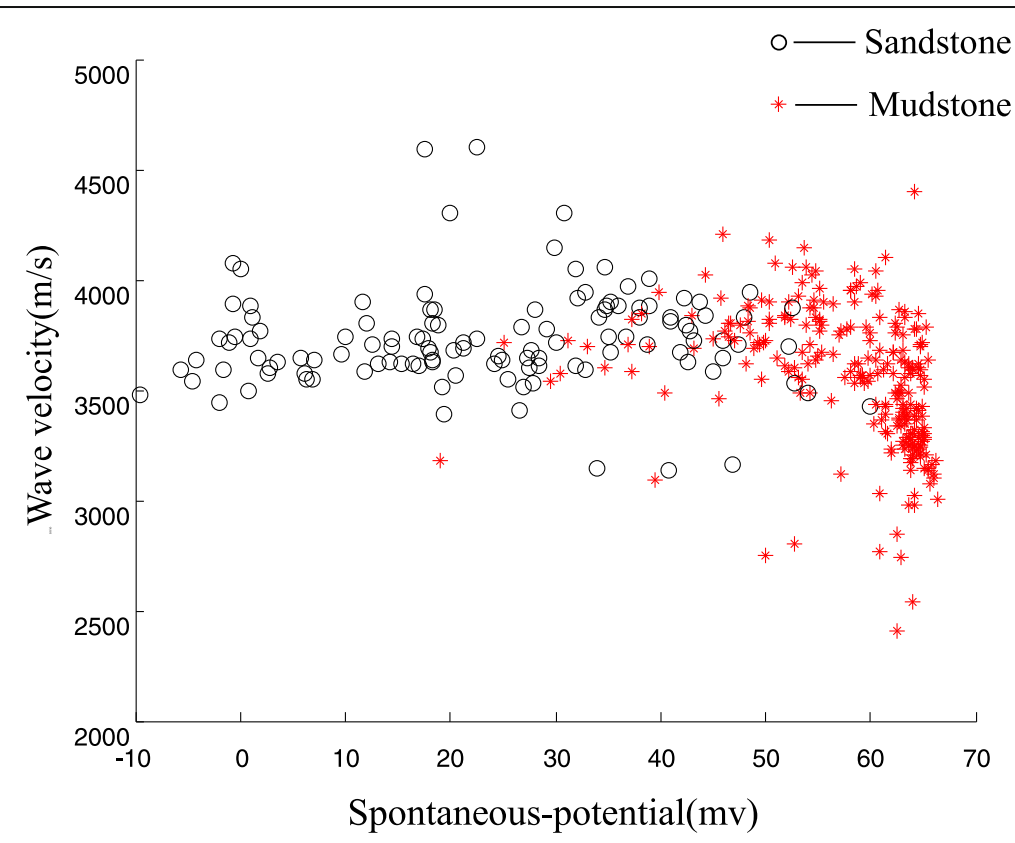

Fig. 2 Wave velocity vs. SP of sandstone and mudstone in the target area 


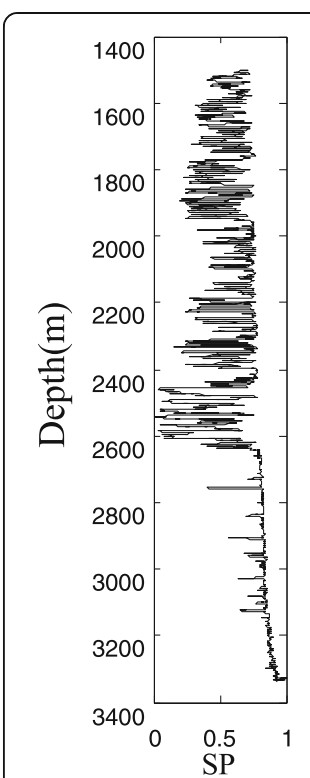

(a)Niu103

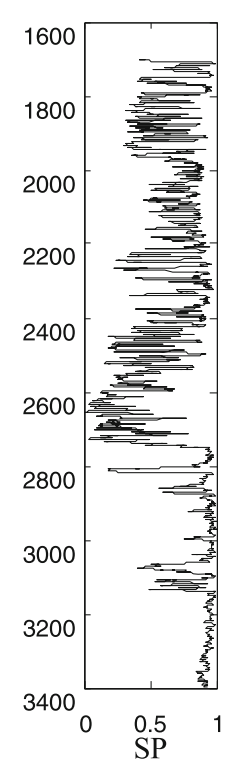

(b) Niu26

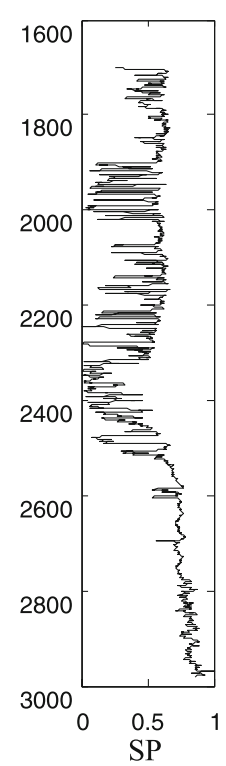

(c) Wang580

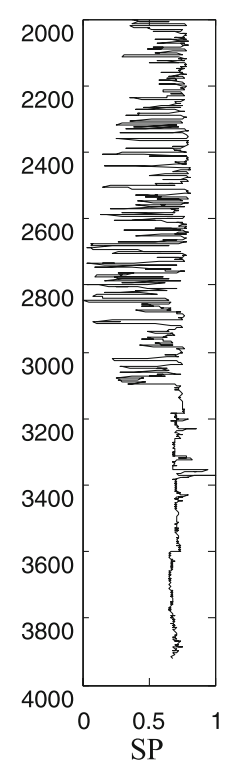

(d) Wang78

Fig. 3 SP curves of some logs involved in multi-attribute inversion (after normalization)

and location of the convolutional sand body of the intermediate section in Member 3 of the Shahejie Formation in the Dongying Delta remain unclear. In this study, the foresetting range and process of the sand body of the intermediate section in Member 3 of the Shahejie Formation in the Dongying Delta were illustrated by the horizon slice of the SP data obtained via seismic multi-attribute inversion.

According to the velocity curves of the intermediate section in Member 3 of the Shahejie Formation in the Dongying Delta forest, the velocity of sandstone is slightly higher than that of mudstone, while characteristic impedances of sandstone and mudstone are not significantly different. Indeed, the longitudinal wave velocities of sandstone and mudstone are concentrated in the range of $3000-4500 \mathrm{~m} / \mathrm{s}$, as shown in Fig. 2. Therefore, it is highly difficult to directly distinguish sandstone and mudstone via wave velocity or characteristic impedance. Further analysis of the SP curves reveals that the SPs of mudstone are concentrated in a high-value zone, while those of sandstone are

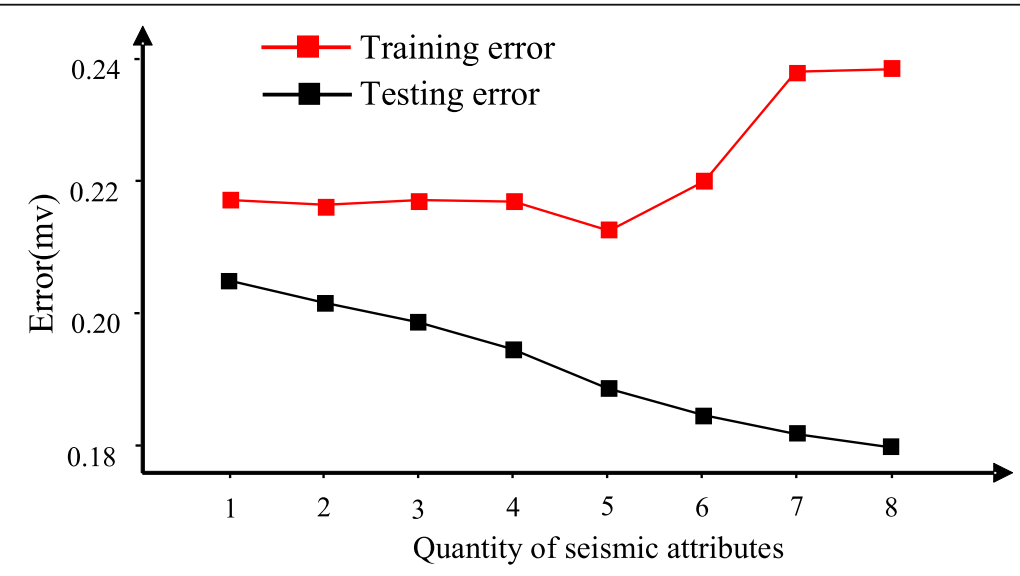

Fig. 4 Quantity of seismic attributes vs. error 
Table 1 The first five seismic attributes used for multi-attribute inversion

\begin{tabular}{llll}
\hline & Seismic attribute & Training error & Cross-test error \\
\hline 1 & Average frequency & 0.209 & 0.221 \\
3 & Absolute amplitude & 0.204 & 0.226 \\
4 & Transient phase & 0.201 & 0.227 \\
5 & Band-pass filtering & 0.200 & 0.223 \\
\hline
\end{tabular}

concentrated in a low-value zone. Therefore, it can be concluded that sandstone and mudstone can be effectively distinguished, and the forest sand body in the delta can be identified by SPs.

In the target area, inversion wells were selected to be uniformly distributed. To enhance the inversion performance, the SP curves of some logs involved in multiattribute inversion were normalized, as presented in Fig. 3.

The optimization of the seismic attribute combination was first conducted. In Fig. 4, the $x$ - and $y$-axes denote the quantity of seismic attributes and the error, respectively. As the quantity of seismic attributes increases, the training error decreases, while the testing error decreases and then increases, indicating that abundant seismic attributes lead to degraded system stability and reduced prediction accuracy. Therefore, the first five seismic attributes were employed as the input of the DNN, as exhibited in Table 1.

Figure 5 shows an east-west well section of the intermediate section in Member 3 of the Shahejie Formation in the Dongying Delta as obtained by multi-attribute SP inversion. As is evident, the inversion results are highly consistent with the SP curves of all wells. Additionally, section-by-section inversion reveals that this delta is a prograded delta with provenance in the southeast area. The development of the subfacies is delta plain, delta front, and front delta, successively.

Figure 6 illustrates the slice of the intermediate section in Member 3 of the Shahejie Formation in the Dongying Delta as obtained by multi-attribute SP inversion. As can

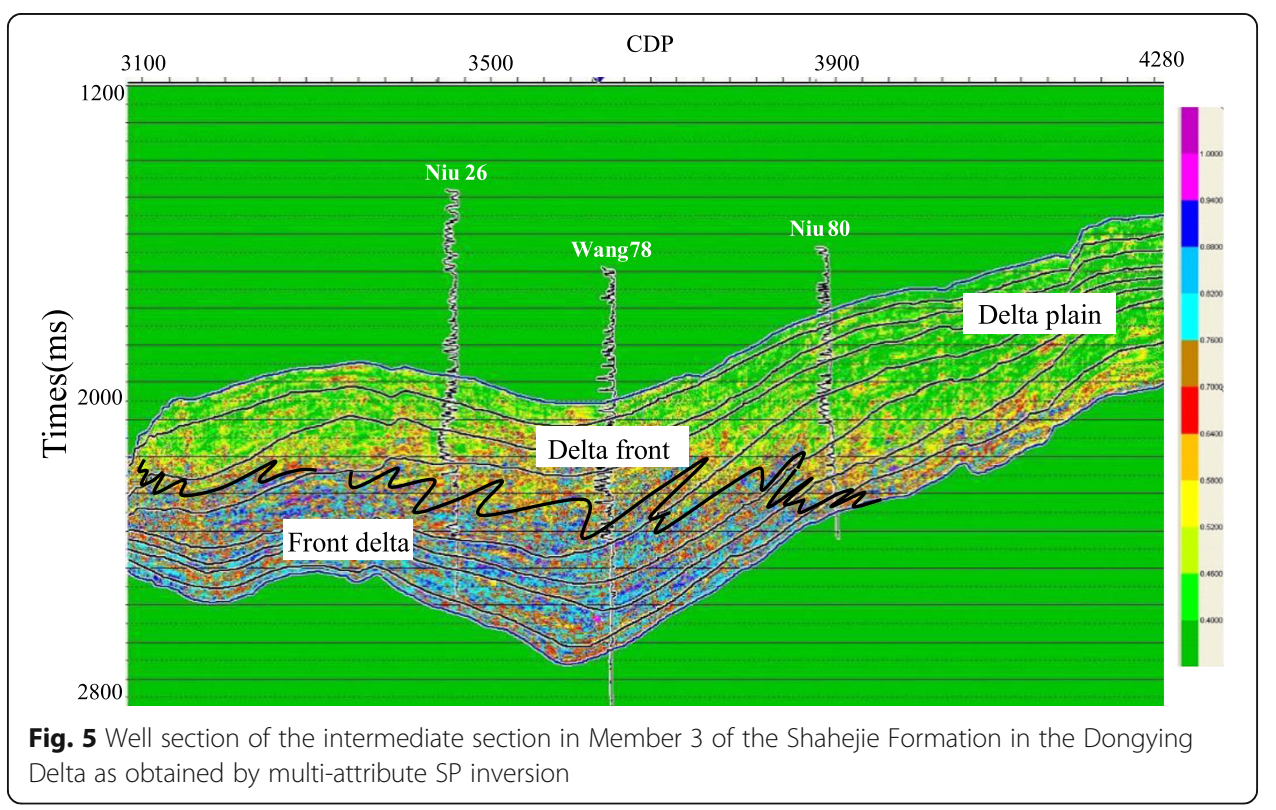




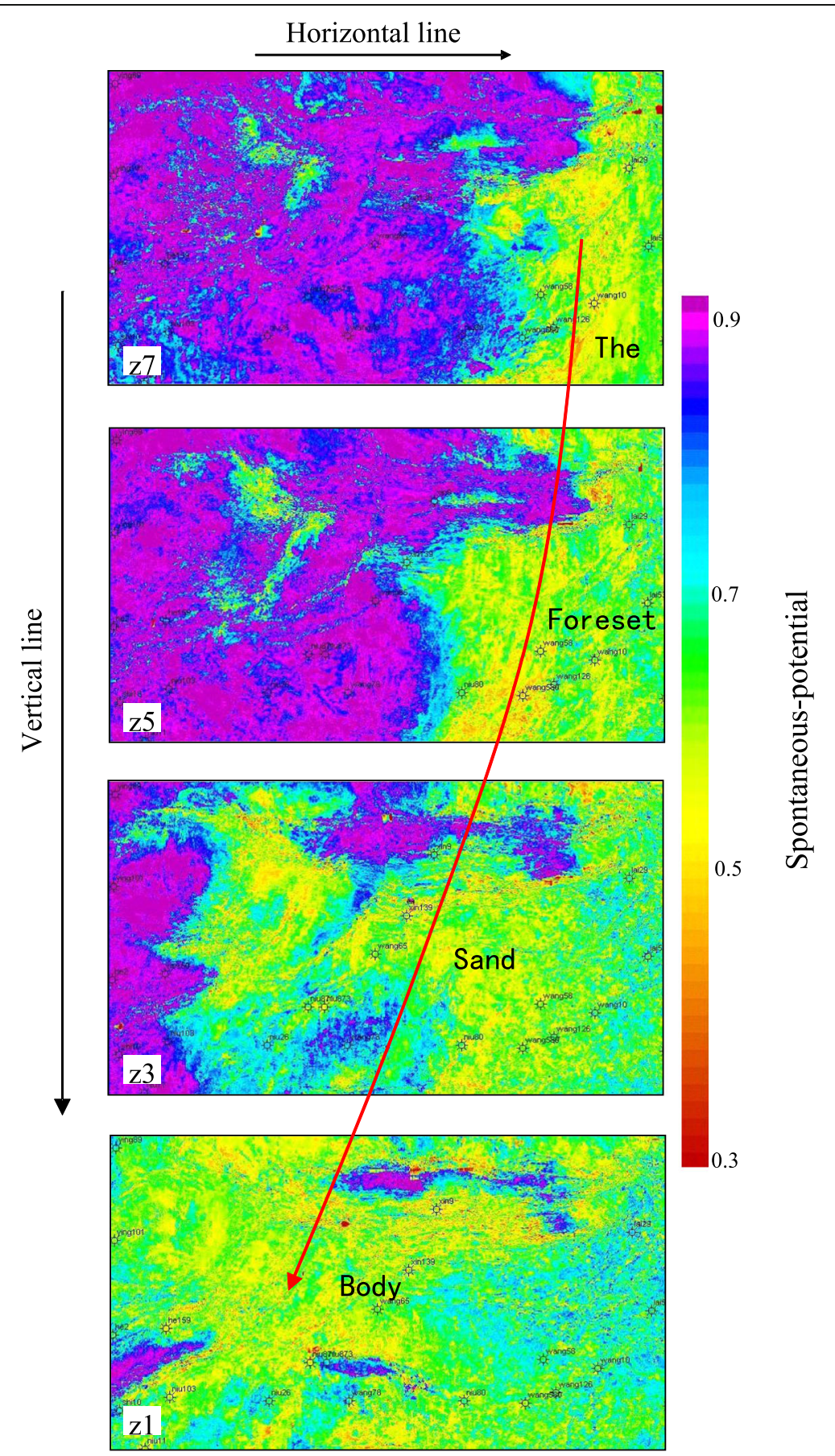

Fig. 6 Horizon slice of the intermediate section in Member 3 of the Shahejie Formation in the Dongying Delta as obtained by multi-attribute SP inversion. The yellow is sand, green is silt, purple is mud, and blue is silty-mud.

be observed, the foresetting process of the delta sand body consists of several stages. At the z7 stage, the target area was dominated by a deep/semi-deep lake, delta lobes coming from the southeast and northeast areas pronograde towards the northwest and borders, and foreset sand body was concentrated in the east area. At the z5 stage, the target area was still dominated by a deep/semi-deep lake, while the delta sand body 
significantly pronograde towards the northwest. Additionally, provenance from the Weibei Hump delta in the southeast provided sufficient supply; progradation was significant, and the prograded sand body crossed the middle part of the target area. At the z3 stage, the lake basin area shrank drastically, and deep/semi-deep lake sediments were only distributed in the northwest part of the target area. Additionally, delta lobes from the northeast and south are as merged and prograded westwards, provenance from the Weibei Hump provided continuous supply via two main river channels, and the sand body thickness was maximized in this area. At the z1 stage, the foreset sand body prograded to the west part of the target area, deep/semi-deep lake sediment in the target area nearly disappeared, delta lobes from northeast and south areas merged, and the pattern was not very sharp. Additionally, river channels for provenance supply intertwined with each other.

\section{Conclusions}

Seismic multi-attribute inversion has been an effective method for lithological inversion, especially for areas where it is difficult to distinguish sandstone and mudstone by characteristic impedances. In this study, the foresetting process of the sand body of the intermediate section in Member 3 of the Shahejie Formation in the Dongying Delta was described by the nonlinear inversion of seismic multi-attributes with SP curves as the objective of nonlinear inversion. Seismic multi-attribute nonlinear inversion is essentially a modified version of conventional seismic inversion methods. This method does not rely on any specific forward model or seismic wavelets and is suitable for many applications.

\section{Abbreviation \\ SVMs: Support vector machine}

\section{Acknowledgements}

This paper was supported by the National Science Foundation of China (Nos., 41602114, 41602112, 41772104) and the Henan Key Laboratory of Biogenic Traces. Thanks to PeijieYang's valuable advice who is from Petroleum Exploration \& Development Research Institute of Shengli Oil Field branch company, China Petroleum \& Chemical Corporation, Dongying, Shandong, China.

\section{Authors' contributions}

YuanyuanWang was responsible for the collection of experimental data, and CuiWang was responsible for the simulation and simulation of the experiment. The author(s) read and approved the final manuscript.

\section{Funding}

This paper was supported by the National Science Foundation of China (Nos., 41602114, 41602112, 41772104) and the Henan Key Laboratory of Biogenic Traces.

Availability of data and materials

The datasets used and/or analyzed during the current study are available from the corresponding author on reasonable request.

Ethics approval and consent to participate

This article does not contain any studies with human participants or animals performed by any of the authors.

\section{Consent for publication}

All authors agree to submit this version and claim that no part of this manuscript has been published or submitted elsewhere. 
Received: 25 May 2020 Accepted: 14 August 2020

Published online: 31 August 2020

\section{References}

1. Q. Chen, S. Sideney, Seismic attribute technology for reservoir forecasting and monitoring. Leading Edge 16(5), 445-456 (1997)

2. BarnesA. Seismic attributes in your facies, CSEG Recorder 9, 41-47 (2001)

3. P. Lawrence, S. Aramco, Dhahran, et al., Seismic attributes in the characterization of small-scale reservoir in Abqaiq Field. Leading Edge 17(4), 521-525 (1998)

4. Z. Liu, J. Liu, Seismic-controlled nonlinear extrapolation of well parameters using neural networks. Geophysics 63(6), 2035-2041 (1998)

5. S. Liu, Z. Xie, J. Liu, et al., Application of pre-stack multi-attribute inversion technology on igneous rock investigation in Nanpu oilfield. Geophysical Prospecting Petroleum 47(1), 83-93 (2008)

6. J. Ming, K. Huang, J. Zhang, et al., An application of neural-network seismic inversion with multiple attributes to horizontal drilling in NB oilfield. China Offshore Oil Gas 18(6), 382-384 (2006)

7. Y. Le, Y. Wang, Nonparametric regression applied in porosity parameter prediction. Chin. J. Geol. 37(1), 118-125 (2002)

8. D. Hampson, B. Yu, X. Liu, Use of multiattribute transforms to predict log properties from seismic data. Progress Exploration Geophysics 25(3), 65-75 (2002)

9. P. Yang, X. Yin, Pre-stack seismic inversion method based on support vector machine. J. Chin. Univ. Petroleum (Edition of Natural Science) 32(1), 37-41 (2008)

10. G. Kong, in China University of Petroleum (Huadong). Extraction and optimization of pre-stack seismic attribute (2008)

11. L. Jiao, Theories of neural network systems (Xidian University Press, 1990)

12. S. Kirkpatrick, C. Gelatt, M. Vecchi, Optimization by simulated annealing. Science 220(4598), 671-680 (1983)

13. G. Qiu, J. Wang, X. Zhang, et al., Preliminary study on stratigraphic architecture of middle-shasan Dongying Delta and its significance to hydrocarbon exploration. Acta SedimentologicaSinica 19(4), 569-575 (2001)

14. H. Liu, P. Yang, S. Liu, et al., Seismic wheeler transform and its application. Geophysical Prospecting Petroleum 51(1), 5155 (2012)

15. X. Mu, X. Lu, P. Yang, High resolution time-frequency analysis method based on high-order statistics. Petroleum Geology Recovery Efficiency 16(6), 56-59 (2009)

16. H. Liang, J. Zou, K. Zuo, M.J. Khan, An improved genetic algorithm optimization fuzzy controller applied to the wellhead back pressure control system. Mechanical Systems Signal Processing 142, 106708 (2020)

17. C. Xu, A novel recommendation method based on social network using matrix factorization technique. Information Processing Management 54(3), 463-474 (2018)

18. H. Liang, D. Zou, Z. Li, M.J. Khan, Y. Lu, Dynamic evaluation of drilling leakage risk based on fuzzy theory and PSO-SVR algorithm. Future Generation Comput. Syst. 95, 454-466 (2019)

\section{Publisher's Note}

Springer Nature remains neutral with regard to jurisdictional claims in published maps and institutional affiliations.

\section{Submit your manuscript to a SpringerOpen ${ }^{\circ}$ journal and benefit from:}

- Convenient online submission

- Rigorous peer review

- Open access: articles freely available online

- High visibility within the field

- Retaining the copyright to your article

Submit your next manuscript at $>$ springeropen.com 